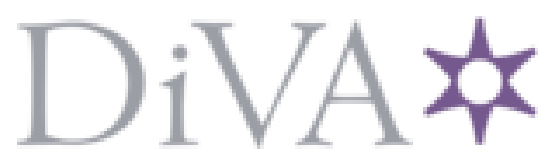

http://www.diva-portal.org

\title{
Postprint
}

This is the accepted version of a paper published in Cerebrovascular Diseases. This paper has been peer-reviewed but does not include the final publisher proof-corrections or journal pagination.

Citation for the original published paper (version of record):

Eriksson, M., Carlberg, B., Eliasson, M. (2012)

The Disparity in Long-Term Survival after a First Stroke in Patients with and without Diabetes Persists: The Northern Sweden MONICA Study.

Cerebrovascular Diseases, 34(2): 153-160

http://dx.doi.org/10.1159/000339763

Access to the published version may require subscription.

N.B. When citing this work, cite the original published paper.

Permanent link to this version:

http://urn.kb.se/resolve?urn=urn:nbn:se:umu:diva-57997 


\section{The disparity in long-term survival after a first stroke in patients with and without diabetes persists: the Northern Sweden MONICA Study}

Cover title: Long-term survival after stroke in diabetes

\section{Authors:}

Marie Eriksson, $\mathrm{PhD}$

Bo Carlberg, MD PhD

Mats Eliasson, $\mathrm{MD}, \mathrm{PhD}$

Department of Statistics, USBE, Umeå University, Umeå, Sweden (Eriksson)

Department of Public Health and Clinical Medicine, Umeå University, Umeå, Sweden (Eliasson, Carlberg)

Department of Medicine, Sunderby Hospital, Luleå, Sweden (Eliasson)

Address for correspondence:

Marie Eriksson

Department of statistics

Umeå University

SE-90187 Umeå

Sweden

Phone +4690 7866108, Fax +46907866614

E-mail: marie.eriksson@stat.umu.se

Key words: acute ischemic stroke, diabetes mellitus, mortality

Subject codes: Acute Cerebral Infarction, diabetes mellitus 


\section{Abstract}

Background Diabetes is an established risk factor for stroke. Compared to non-diabetic patients, diabetic patients also have an increased risk of new vascular events and death after stroke. We analyzed how differences in long-term survival between diabetic and non-diabetic stroke patients have changed over time, and if differences varied with respect to sex and age.

Methods This population based study included 12375 first-ever stroke patients, 25-74 years old, who were registered in the Northern Sweden MONICA Stroke Registry 1985-2005. Uniform diagnosis criteria for stroke case ascertainment were used throughout the study period. The diagnosis of diabetes was based on medical records or diabetes diagnosed during the acute stroke event. Patients were separated into four cohorts according to year of stroke and followed for survival until August 30, 2008.

Results The diabetes prevalence at stroke onset was $21 \%$, similar in men and women, and remained stable throughout the study period. The diabetic patients were an average of 2 years older, more often non-smokers and more likely to have antihypertensive treatment, antithrombotics, atrial fibrillation, and a history of myocardial infarction or TIA than the nondiabetic patients. The total follow-up time was 86086 patient-years during which a total 1930 (75.7\%) of the diabetic patients and $5744(58.5 \%)$ of the non-diabetic patients died $(P<0.001)$. Median survival was 60 months (95\% CI: 57-64) in diabetic patients and 117 months (113$120)$ in the non-diabetic patients. The survival improved significantly in both groups ( $\mathrm{P}<0.001)$. A Cox regression, adjusting for possible confounders (age, sex, antihypertensive medication, antithrombotics or other thrombolytic agents, history of myocardial infarction, type of stroke, diabetes, cohort and the diabetes-by-sex, diabetes-by-age and diabetes-bycohort interactions), showed a hazard ratio of 1.67 (1.58-1.76) comparing survival in diabetic vs. non-diabetic patients. The reduced survival in diabetic stroke patients was more 
pronounced in women $(\mathrm{P}=0.02)$ and younger patients $(\mathrm{P}<0.001)$. There was a tendency that the difference in survival decreased between the earlier cohorts and the 2000-2005 cohort, but the test for interaction did not reach statistical significance $(\mathrm{P}=0.08)$.

Conclusion Long-term survival after a first stroke has improved in both diabetic and nondiabetic patients. Survival is markedly lower in diabetics, especially in women and younger patients, and the disparity persisted over 24 years. Decreasing the disparity in stroke survival is a challenge for stroke and diabetes care. New treatment methods in combination with intense secondary prevention in diabetic patients, especially in younger women, are needed. 


\section{INTRODUCTION}

Patients with diabetes have a two to threefold increased risk of stroke, and diabetes is present in $15-27 \%$ of all incident strokes in the US [1,2]. Although ischemic and recurrent strokes are more common in persons with diabetes than in those without diabetes, transient ischemic attacks and hemorrhagic stroke are less common. Around $40 \%$ of ischemic strokes are due to diabetes [3]. In Sweden, diabetes was present among $12 \%$ of the patients dying due to stroke during the period 1997-2010, and there has been no decrease or increase over time in that percentage [4].

Most studies agree that fatality up to one year after a stroke is increased in diabetic patients [5-8] and that diabetes increases the risk of cardiovascular events and death within 2 years after ischemic stroke [9]. Meanwhile, data on long-term survival is scant. Two recent Danish studies found that diabetes is associated with much lower survival at 10-12 years' follow-up [5,10]. In a Veteran Study, restricted to men suffering an ischemic stroke during 1990 to 1997 , long-term mortality was lower in patients with diabetes, although much improved compared to earlier studies [11].

We wished to assess the impact of intensified primary and secondary prevention, including surgery for carotid stenosis and dedicated stroke units, on mortality among diabetic patients after a first stroke. Towards this goal, survival data over periods much longer than one year are needed to describe the secular trends over a period that includes the introduction of evidence-based cardiovascular diabetology [1]. In addition, data should include patients not treated in hospital or deceased before reaching the hospital.

Using population based data, our objectives were to compare long-term survival after a first stroke between diabetic and non-diabetic patients, to assess if possible differences in survival 
have changed over time 1985-2005, and to determine if differences vary with respect to sex and age.

\section{METHOD}

This study was based on the Northern Sweden MONICA Stroke Registry. The registry is population-based, and details of the event-registration procedure have been described previously [12]. The registry includes all acute stroke events in the age range 25-74 years in the two northernmost counties of Sweden, Norrbotten and Västerbotten, and the average total population in the target group aged 25-74 years was 313800 during 1985-2005. Suspected acute stroke events were identified through reports from hospitals and general practitioners, hospital discharge registers and death certificates. Suspected acute strokes were validated by a research nurse according to the WHO criteria as "rapidly developing clinical signs of focal (or global) disturbance of cerebral function lasting more than 24 hours, with no apparent cause other than vascular origin" throughout the time period $[13,14]$.

This study included intra-cerebral hemorrhages (ICH), ischemic strokes, and unspecified strokes (ICD-10: I61, I63 and I64) occurring between January 1, 1985 and December 31 2005. Patients were excluded from the study if they had experienced a previous stroke event (according to the register or medical records). The diagnosis of diabetes was based on medical records or diabetes diagnosed during the acute stroke event.

The endpoint studied was death from any cause and stroke patients were followed-up using the Swedish Cause of Death Registry (National Board of Health and Welfare) as of August 30, 2008. Patients not identified in the register were assumed to be alive at that date.

The patients were separated into four cohorts according to year of stroke: 1985-1989, 19901994, 1995-1999, and 2000-2005. 
The Northern Sweden MONICA Study was approved by the regional ethical review board in Umeå. Patients or relatives to non-survivors gave written consent.

\section{Statistical analyses}

Differences in baseline characteristics between diabetic and non-diabetic stroke patients were tested using chi-square test for categorical variables and t-test for continuous variables.

The median survival time from stroke onset was presented for subgroups of patients. The log rank test was used for univariate comparisons of time to event between patient groups.

Multiple Cox proportional hazard regression was used to analyze time to event, adjusting for potential confounders. The model included the independent variables age, sex, antihypertensive medication at onset, antithrombotics at onset (anticoagulants, acetylsalicylates, platelet anitaggregants, other thrombolytic agents), history of myocardial infarction, type of stroke (ICH/other), diabetes (yes/no), cohort (1985-1989, 1990-1994, 19951999, and 2000-2005) and the diabetes-by-sex, diabetes-by-age and diabetes-by-cohort interactions. The smoking parameter contained a large amount of missing values (53\%) and was therefore excluded from the multiple regression. Patients who were still alive at the end of study, August 30, 2008, were censored at that time point. Kaplan-Meier survival curves were examined to identify deviations from the proportional hazard's assumption. Outcome was presented by hazard ratios (HR) with $95 \%$ confidence intervals (95\% CI). IBM SPSS Statistics 19 was used for statistical analysis.

\section{RESULTS}

Between 1985 and 2005, 12477 18-74 year old stroke patients with a first stroke were registred. Personal identification numbes were missing for seven patients, and therefore those seven were lost to follow-up. Eleven patients had negative survival times, which suggest clerical errors, and those eleven were excluded from the analysis. Of the remaining patients, 
84 lacked information on diabetes. Hence, complete data regarding diabetes and follow-up were available for 12375 patients.

Of the stroke patients, 2549 (20.6\%) had diabetes of which $101(4.0 \%)$ had type 1 diabetes, $2092(82.1 \%)$ type 2 diabetes, $253(9.9 \%)$ had unspecified diabetes, and $103(0.8) \%$ were diagnosed with diabetes during the event. The proportion of men in diabetic $(61.6 \%)$ and the non-diabetic groups $(61.0 \%)$ were similar.

Patients with diabetes were on average 2 years older (66.2 vs. $64.2, P<0.001)$, were less likely to smoke $(32.2 \%$ vs. $37.7 \%, P=0.001)$, and had more often antihypertensive treatment $(71.3 \%$ vs. $44.8 \%, P<0.001)$ or antithrombotics $(32.2 \%$ vs. $20.1 \%, P<0.001)$ at stroke onset. Patients with diabetes had atrial fibrillation $(17.1 \%$ vs. $13.2 \%, P<0.001)$, history of myocardial infarction (20.7\% vs. $12.3 \%, P<0.001)$, and previous TIA (5.7\% vs. $4.2 \%, P=0.036)$ more often than nondiabetic patients. Diabetic patients were more often fully conscious at hospital arrival $(90.5 \%$ vs. $87.6 \%, P=0.006)$, and less likely to have ICH (7.4\% vs. $15.4 \%, P<0.001)$. The prevalence of diabetes, the proportion of men, and the mean age remained stable during the four time periods.

Patients were followed for a median time of 6.1 years (74 months) and maximum of 23.7 years (284 months). The total follow-up time was 86086 patient-years during which a total $1930(75.7 \%)$ of the diabetic patients and $5744(58.5 \%)$ of the non-diabetic patients died $(P<0.001)$. The median survival was 5.0 years $(95 \% \mathrm{CI}: 4.7-5.4)$ in the diabetic and 9.7 years (95\% CI: 9.4-10.0) in the non-diabetic stroke patients. The mortality rates in diabetic (nondiabetic) patients were $15 \%(12 \%)$ at 28 days, $25 \%(18 \%)$ at 1 year, $38 \%(25 \%)$ at 3 years, $50 \%(32 \%)$ at 5 years, and $73 \%(51 \%)$ at 10 years after stroke. For each of the successive cohorts, mortality rates decreased both for diabetic and non-diabetic patients (Fel! Hittar inte referenskälla.). The reduced survival in diabetic, as compared to non-diabetic, patients was 
evident in both men and women in all time periods $(P<0.001$ using log rank tests for each cohort (Table 2).

A multiple Cox regression confirmed the disparity in survival between diabetics and nondiabetics, $\mathrm{HR}=1.67$ (95\% CI: 1.58-1.76). Other factors associated with increased mortality were higher age, male sex, antihypertensive medication at onset, atrial fibrillation, history of myocardial infarction, and hemorrhagic stroke (Table 3). Including interactions in the regression showed that the relative difference between diabetic and non-diabetic patients was smaller in men (diabetes-by-sex interaction $\mathrm{HR}=0.88, P=0.025)$ and decreased with higher age (diabetes-by-age interaction $\mathrm{HR}=0.98, P<0.001$ ), Table 3 and Fel! Hittar inte referenskälla.. There was also a tendency toward decreased difference during 2000-2005 as compared to earlier years (Figure 1), but the diabetes-by-cohort interaction effect did not reach statistical significance $(P=0.08)$.

\section{DISCUSSION}

Long-term survival after a first stroke has improved, and the improvement has been at least as good in diabetic patients as in non-diabetic patients. However, the survival of a diabetic patient suffering a stroke after 2000 was similar to the survival of a patient without diabetes who had his stroke in the late eighties. The markedly lower survival in stroke patients with diabetes, as compared to patients without diabetes, persisted between 1985 and 2005 . The reduced survival after stroke in patients with diabetes was even more pronounced in women and younger patients.

This study included stroke patients during a period of 21 years, and followed them for up to 23 years. Both stroke patients treated in hospital and patients who died outside of hospital were captured. A previous validation of the MONICA stroke registry using the National Patient Register (National Board of Health and Welfare) showed that MONICA has almost 
complete coverage in the selected age interval (unpublished data). During the extensive time period of this study, diagnostic methods have developed in clinical praxis. The increased use of MRI and CT enables detection of strokes with very minor neurological symptoms, which may partly explain improved survival in both groups. A major strength of this study is the uniform methods and strict diagnosis criteria for stroke case ascertainment throughout the study period. This minimizes the effect of changes in clinical stroke diagnosis. The prevalence of diabetes has also remained at a stable level in the study population [15].

This study was limited to patients under 75 years with a first stroke, which excluded approximately half of all stroke patients. We observed a smaller difference in survival between diabetic and non-diabetic patients in the older age group 65-74 years as compared to younger patients, and it is possible that other factors than diabetes influence survival more in the elderly. However, one should be cautious to extrapolate the findings of our study to more advanced age groups.

Stroke severity is an established predictor of outcome after stroke $[5,16]$ and we used level of consciousness as a proxy. The impact of stroke severity has been shown to be weaker for long-term survival [5], and during the latter part of this study, where level of consciousness was registered, diabetic patients were slightly less often unconscious at presentation. Hence stroke severity was unlikely to explain the observed difference in survival between patients with and without diabetes.

Improved long-term survival after stroke has been observed in previous Swedish studies [1719]. The present observed difference in survival between diabetic a non-diabetic stroke patients $(\mathrm{HR}=1.66)$ was consistent with the difference reported from a Danish cohort study $(\mathrm{HR}=1.74)[10]$. The similar improvement, but persisting difference in long-term survival between diabetic and non-diabetic stroke patients, is in agreement with the development in 1- 
year case-fatality observed in Finnish ischemic stroke patients with and without type 2 diabetes [8]. A large cohort study from the UK using the General Practice Research Database showed that the increased relative risk of stroke in patients with type 2 diabetes compared to patients without diabetes was highest in women and decreased with age [20]. In the Finnish study, the highest excess 28 -day stroke case fatality caused by diabetes was in younger women. We observed a similar pattern when it came to long-term survival after stroke, where the relative risk for patients with diabetes was more elevated in women and in younger patients. Hence, in addition to a higher risk of stroke, younger women with diabetes seem to have a worse prognosis after stroke. Interestingly, a recent study showed almost identical trends and disparities in long-term survival after a first myocardial infarction among diabetic subjects within the Northern Sweden MONICA Study [21] implying common pathways not reversed by traditional risk factor treatment.

A recent population based study showed increased use of lipid-lowering agents and antihypertensive drugs, and substantial improvements in cardiovascular risk factors (blood pressure, smoking, cholesterol levels and education) in northern Sweden between 1986 and 2009 [15]. Life style changes, improved secondary prevention, more patients being treated in stroke units and the use of stroke thrombolysis have probably all contributed to the increased survival after stroke in the general population. The recently noted improved blood pressure control among Swedish patients with type 2 diabetes will reduce both risks of stroke and of mortality after a stroke [22]. While no increase in stroke patients with diabetes was observed in our study, an increasing proportion of stroke patients with diabetes have been observed in the United States [23].

Another study from the United States found quality of care to be comparable in patients with and without diabetes in most aspects with the exception that diabetic patients are less likely to receive stroke thrombolysis [24] a difference that has also been seen in the Swedish stroke 
register [25]. Despite a probable treatment difference in thrombolysis, the difference in survival between diabetic and non-diabetic patients did not increase during the last period during which thrombolysis for acute ischemic stroke was introduced in Sweden. The SPARCL study showed no difference in the effect of statin treatment to prevent recurrent stroke in patients with or without type 2 diabetes, but patients with diabetes still had an increased risk of recurrent stroke or cardiovascular disease [26].

The worse survival in diabetic patients remained after adjustments for differences in risk factors. However, there may be other unmeasured confounders. Differences in socioeconomic status and other differences in case-mix might partially explain the observed differences.

The similar favorable trend in survival in diabetic and non-diabetic patients suggests that acute stroke care and secondary prevention have been successful both in patients with and without diabetes. However, the treatment has not decreased the gap in long-term survival. The reason for the gap remains unclear, and decreasing the disparity in stroke survival is a challenge for stroke and diabetes care. New treatment methods in combination with intense secondary prevention in diabetic patients, especially in younger women, are needed.

\section{Sources of funding}

The northern Sweden MONICA study has received grants from Norrbotten and Västerbotten County Councils, the Swedish Research Council (MFR), the Joint Committee of Northern Sweden Health Care Region (Visare Norr), the Heart and Chest Foundation, the Stroke fund, King Gustaf V's and Queen Victoria's Foundation, the Vårdal Foundation, and the Social Sciences Research Council.

\section{Conflicts of interest}


The authors declare that they have no conflict of interest in relation to this study. 


\section{REFERENCES}

1 Air EL, Kissela BM: Diabetes, the metabolic syndrome, and ischemic stroke: epidemiology and possible mechanisms. Diabetes Care 2007;30:3131-3140.

2 Sander D, Sander S, Poppert H: Stroke in type 2 diabetes. Br J Diabetes Vasc Dis 2008;8:222-229.

3 Kissela BM, Khoury J, Kleindorfer D, Woo D, Schneider A, Alwell K, Miller R, Ewing I, Moomaw CJ, Szaflarski JP, Gebel J, Shukla R, Broderick JP: Epidemiology of ischemic stroke in patients with diabetes: the greater Cincinnati/Northern Kentucky Stroke Study. Diabetes Care 2005;28:355-359.

4 Registry of causes of death. Stockholm, Sweden, National board of health and welfare. 2011.

5 Andersen KK, Olsen TS: One-month to 10-year survival in the Copenhagen stroke study: interactions between stroke severity and other prognostic indicators. J Stroke Cerebrovasc Dis 2011;20:117-123.

6 Jia Q, Zhao X, Wang C, Wang Y, Yan Y, Li H, Zhong L, Liu L, Zheng H, Zhou Y: Diabetes and poor outcomes within 6 months after acute ischemic stroke: the China National Stroke Registry. Stroke 2011;42:2758-2762.

7 Rautio A, Eliasson M, Stegmayr B: Favorable trends in the incidence and outcome in stroke in nondiabetic and diabetic subjects: findings from the Northern Sweden MONICA Stroke Registry in 1985 to 2003. Stroke 2008;39:3137-3144.

8 Winell K, Paakkonen R, Pietila A, Reunanen A, Niemi M, Salomaa V: Prognosis of ischaemic stroke is improving similarly in patients with type 2 diabetes as in nondiabetic patients in Finland. Int J Stroke 2011;6:295-301.

9 Venketasubramanian N, Rother J, Bhatt DL, Pasquet B, Mas JL, Alberts MJ, Hill MD, Aichner F, Steg PG: Two-year vascular event rates in patients with symptomatic cerebrovascular disease: the REACH registry. Cerebrovasc Dis 2011;32:254-260.

10 Ronning OM, Stavem K: Predictors of mortality following acute stroke: A cohort study with 12 years of follow-upp. J Stroke Cerebrovasc Dis 2010 Nov 12.: [Epub ahead of print].

11 Kamalesh M, Shen J, Eckert GJ: Long term postischemic stroke mortality in diabetes: a veteran cohort analysis. Stroke 2008;39:2727-2731.

12 Stegmayr B, Lundberg V, Asplund K: The events registration and survey procedures in the Northern Sweden MONICA Project. Scand J Public Health Suppl 2003;61:9-17.

13 Tunstall-Pedoe H: The World Health Organization MONICA Project (monitoring trends and determinants in cardiovascular disease): a major international collaboration. WHO MONICA Project Principal Investigators. J Clin Epidemiol. 1988;41:105-114.

14 Asplund K, Tuomilehto J, Stegmayr B, Wester PO, Tunstall-Pedoe H: Diagnostic criteria and quality control of the registration of stroke events in the MONICA project. Acta Med Scand Suppl. 1988;728:26-39.

15 Eriksson M, Holmgren L, Janlert U, Jansson JH, Lundblad D, Stegmayr B, Soderberg $\mathrm{S}$, Eliasson M: Large improvements in major cardiovascular risk factors in the population of northern Sweden: the MONICA study 1986-2009. J Intern Med 2011;269:219-231.

16 Counsell C, Dennis M: Systematic review of prognostic models in patients with acute stroke. Cerebrovasc Dis 2001;12:159-170.

17 Hallstrom B, Jonsson AC, Nerbrand C, Norrving B, Lindgren A: Stroke incidence and survival in the beginning of the 21st century in southern Sweden: comparisons with the late 20th century and projections into the future. Stroke 2008;39:10-15. 
18 Peltonen M, Stegmayr B, Asplund K: Time trends in long-term survival after stroke: the Northern Sweden Multinational Monitoring of Trends and Determinants in Cardiovascular Disease (MONICA) study, 1985-1994. Stroke 1998;29:1358-1365.

19 Terent A: Trends in stroke incidence and 10-year survival in Soderhamn, Sweden, 1975-2001. Stroke 2003;34:1353-1358.

20 Mulnier HE, Seaman HE, Raleigh VS, Soedamah-Muthu SS, Colhoun HM, Lawrenson RA, De Vries CS: Risk of stroke in people with type 2 diabetes in the UK: a study using the General Practice Research Database. Diabetologia 2006;49:28592865.

21 Eliasson M, Jansson JH, Lundblad D, Naslund U: The disparity between long-term survival in patients with and without diabetes following a first myocardial infarction did not change between 1989 and 2006: an analysis of 6,776 patients in the Northern Sweden MONICA Study. Diabetologia 2011;54:2538-2543.

22 Nilsson PM, Cederholm J, Zethelius BR, Eliasson BR, Eeg-Olofsson K, Gudbj Rnsdottir S: Trends in blood pressure control in patients with type 2 diabetes: data from the Swedish National Diabetes Register (NDR). Blood Press. 2011;20:348-354.

23 Towfighi A, Markovic D, Ovbiagele B: Current National Patterns of Comorbid Diabetes among Acute Ischemic Stroke Patients. Cerebrovasc Dis 2012;33:411-418.

24 Reeves MJ, Vaidya RS, Fonarow GC, Liang L, Smith EE, Matulonis R, Olson DM, Schwamm LH: Quality of care and outcomes in patients with diabetes hospitalized with ischemic stroke: findings from Get With the Guidelines-Stroke. Stroke 2010;41:e409-417.

25 Eriksson M, Jonsson F, Appelros P, Asberg KH, Norrving B, Stegmayr B, Terent A, Asplund K: Dissemination of thrombolysis for acute ischemic stroke across a nation: experiences from the Swedish stroke register, 2003 to 2008. Stroke 2010;41:11151122.

26 Callahan A, Amarenco P, Goldstein LB, Sillesen H, Messig M, Samsa GP, Altafullah I, Ledbetter LY, MacLeod MJ, Scott R, Hennerici M, Zivin JA, Welch KM: Risk of stroke and cardiovascular events after ischemic stroke or transient ischemic attack in patients with type 2 diabetes or metabolic syndrome: secondary analysis of the Stroke Prevention by Aggressive Reduction in Cholesterol Levels (SPARCL) trial. Arch Neurol. 2011;68:1245-1251. 


\section{FIGURE LEGENDS}

Figure 1. Kaplan-Meier survival curves of diabetic (black) and non-diabetic (grey) stroke patients for men and women in different time periods of stroke onset.

Figure 2. Kaplan-Meier survival curves of diabetic (black) and non-diabetic (grey) stroke patients for men and women in different age groups (25-64 years and 65-74 years). 


\section{TABLES}

Table 1. Baseline characteristics (mean or proportion) for diabetic and non-diabetic patients in each time period. P-values for overall comparisons of patient groups (1985-2005) were calculated using t-test for age and chi-square test for other variables.

\begin{tabular}{|c|c|c|c|c|c|c|c|}
\hline & & \multicolumn{4}{|c|}{ Cohort } & \multicolumn{2}{|c|}{ All years } \\
\hline & & $\begin{array}{c}1985- \\
1989\end{array}$ & $\begin{array}{c}1990- \\
1994\end{array}$ & $\begin{array}{c}1995- \\
1999\end{array}$ & $\begin{array}{c}2000- \\
2005\end{array}$ & $\begin{array}{l}1985- \\
2005\end{array}$ & $\mathrm{P}$ \\
\hline \multirow{2}{*}{$\begin{array}{l}\text { No. of stroke } \\
\text { patients }\end{array}$} & Non-diabetic & 2360 & 2530 & 2536 & 2400 & 9826 & \\
\hline & Diabetic & 651 & 628 & 642 & 628 & 2549 & \\
\hline Diabetes (\%) & & 21.6 & 19.9 & 21.2 & 20.7 & 20.6 & \\
\hline \multirow[t]{2}{*}{ Mean age (years) } & Non-diabetic & 64.5 & 64.7 & 63.6 & 63.8 & 64.2 & $<0.001$ \\
\hline & Diabetic & 66.2 & 66.5 & 66.4 & 65.8 & 66.2 & \\
\hline \multirow[t]{2}{*}{ Men (\%) } & Non-diabetic & 62.9 & 60.2 & 60.9 & 60.0 & 61.0 & 0.610 \\
\hline & Diabetes & 58.2 & 61.5 & 63.7 & 62.9 & 61.6 & \\
\hline \multirow{2}{*}{$\begin{array}{l}\text { Regular smoking } \\
(\%)\end{array}$} & Non-diabetic & 43.8 & 36.2 & 38.5 & 34.1 & 37.7 & 0.001 \\
\hline & Diabetic & 36.8 & 28.0 & 30.7 & 35.0 & 32.2 & \\
\hline \multirow{2}{*}{$\begin{array}{l}\text { Fully conscious } \\
\text { at hospital } \\
\text { arrival* }\end{array}$} & Non-diabetic & - & - & 88.0 & 87.2 & 87.6 & 0.006 \\
\hline & Diabetic & - & - & 90.9 & 90.1 & 90.5 & \\
\hline \multirow{2}{*}{$\begin{array}{l}\text { Antihypertensive } \\
\text { medication at } \\
\text { onset }(\%)\end{array}$} & Non-diabetic & 44.8 & 42.0 & 45.6 & 46.9 & 44.8 & $<0.001$ \\
\hline & Diabetic & 71.8 & 62.3 & 73.8 & 77.3 & 71.3 & \\
\hline \multirow{2}{*}{$\begin{array}{l}\text { Antithrombotics } \\
\text { at onset }(\%)\end{array}$} & Non-diabetic & 8.1 & 15.3 & 26.4 & 30.1 & 20.1 & $<0.001$ \\
\hline & Diabetic & 10.4 & 26.1 & 41.8 & 51.2 & 32.2 & \\
\hline \multirow{2}{*}{$\begin{array}{l}\text { Atrial fibrilation } \\
(\%)\end{array}$} & Non-diabetic & 9.4 & 13.4 & 14.7 & 15.1 & 13.2 & $<0.001$ \\
\hline & Diabetic & 15.3 & 18.8 & 16.9 & 17.7 & 17.1 & \\
\hline History of TIA* & Non-diabetic & - & - & 4.3 & 4.0 & 4.2 & 0.036 \\
\hline
\end{tabular}




\begin{tabular}{|c|c|c|c|c|c|c|c|}
\hline & Diabetic & - & - & 5.9 & 5.6 & 5.7 & \\
\hline \multirow{2}{*}{$\begin{array}{l}\text { History of } \\
\text { myocardial } \\
\text { infarction }(\%)\end{array}$} & Non-diabetic & 15.8 & 13.6 & 12.2 & 7.7 & 12.3 & $<0.001$ \\
\hline & Diabetic & 25.5 & 21.9 & 19.1 & 16.1 & 20.7 & \\
\hline \multirow{2}{*}{$\begin{array}{l}\text { Hemorrhagic } \\
\text { stroke }(\%)\end{array}$} & Non-diabetic & 13.8 & 15.2 & 16.4 & 16.0 & 15.4 & $<0.001$ \\
\hline & Diabetic & 6.1 & 5.9 & 7.2 & 10.5 & 7.4 & \\
\hline
\end{tabular}

*) was not measured 1985-1994 
Table 2. Median survival (months) with 95\% confidence intervals for men and women in diabetic and non-diabetic stroke patients.

\begin{tabular}{lccccc}
\hline \multicolumn{1}{c}{$1985-1989$} & $1990-1994$ & $1995-1999$ & $2000-2005$ & $1985-2005$ \\
\hline Women & & & & \\
$\quad$ Non-diabetics & $97(84-110)$ & $116(106-126)$ & $146(.-)$. &.$(.-)$. & $127(121-133)$ \\
$\quad$ Diabetics & $38(30-46)$ & $56(45-66)$ & $80(63-96)$ & $92(71-112)$ & $61(54-68)$ \\
Men & & & & & \\
Non-diabetics & $87(81-94)$ & $97(89-105)$ & $136(127-145)$ &.$(.-)$. & $111(107-115)$ \\
Diabetics & $40(32-48)$ & $51(40-62)$ & $69(59-79)$ & $102(83-122)$ & $60(56-65)$ \\
All & & & & & \\
Non-diabetics & $91(85-96)$ & $104(98-110)$ & $141(133-149)$ &.$(.-)$. & $117(113-120)$ \\
Diabetics & $39(34-45)$ & $54(46-63)$ & $73(63-82)$ & $97(86-108)$ & $60(57-64)$ \\
\hline (.-.)- confidence intervals could not be be calculated & &
\end{tabular}


Table 3. Multiple Cox regression of survival in diabetic vs. non-diabetic stroke patients.

Hazard ratio (HR) with 95\% confidence intervals (CI). ICH = intra-cerebral hemorrhages

\begin{tabular}{|c|c|c|c|c|}
\hline & & Main e & fects mo & \\
\hline & & & $95 \% \mathrm{C}$ & or HR \\
\hline & $\mathrm{P}$ & HR & Lower & Upper \\
\hline Main effects: & & & & \\
\hline Cohort & 0.000 & & & \\
\hline (ref: 1985-1989) & & & & \\
\hline 1990-1994 & 0.000 & 0.832 & 0.785 & 0.881 \\
\hline 1995-1999 & 0.000 & 0.628 & 0.587 & 0.671 \\
\hline $2000-2005$ & 0.000 & 0.530 & 0.487 & 0.577 \\
\hline Age (1 year) & 0.000 & 1.063 & 1.059 & 1.067 \\
\hline Male sex & 0.000 & 1.188 & 1.132 & 1.247 \\
\hline Antihypertensive & 0.000 & 1.116 & 1.062 & 1.174 \\
\hline medication at onset & & & & \\
\hline Antithrombotics at & 0.106 & 1.053 & 0.989 & 1.120 \\
\hline onset & & & & \\
\hline Atrial fibrillation & 0.000 & 1.259 & 1.180 & 1.343 \\
\hline History of myocardial & 0.000 & 1.422 & 1.334 & 1.516 \\
\hline infarction & & & & \\
\hline $\mathrm{ICH}$ & 0.000 & 1.430 & 1.335 & 1.532 \\
\hline Diabetes & 0.000 & 1.667 & 1.578 & 1.761 \\
\hline
\end{tabular}


Figure 1
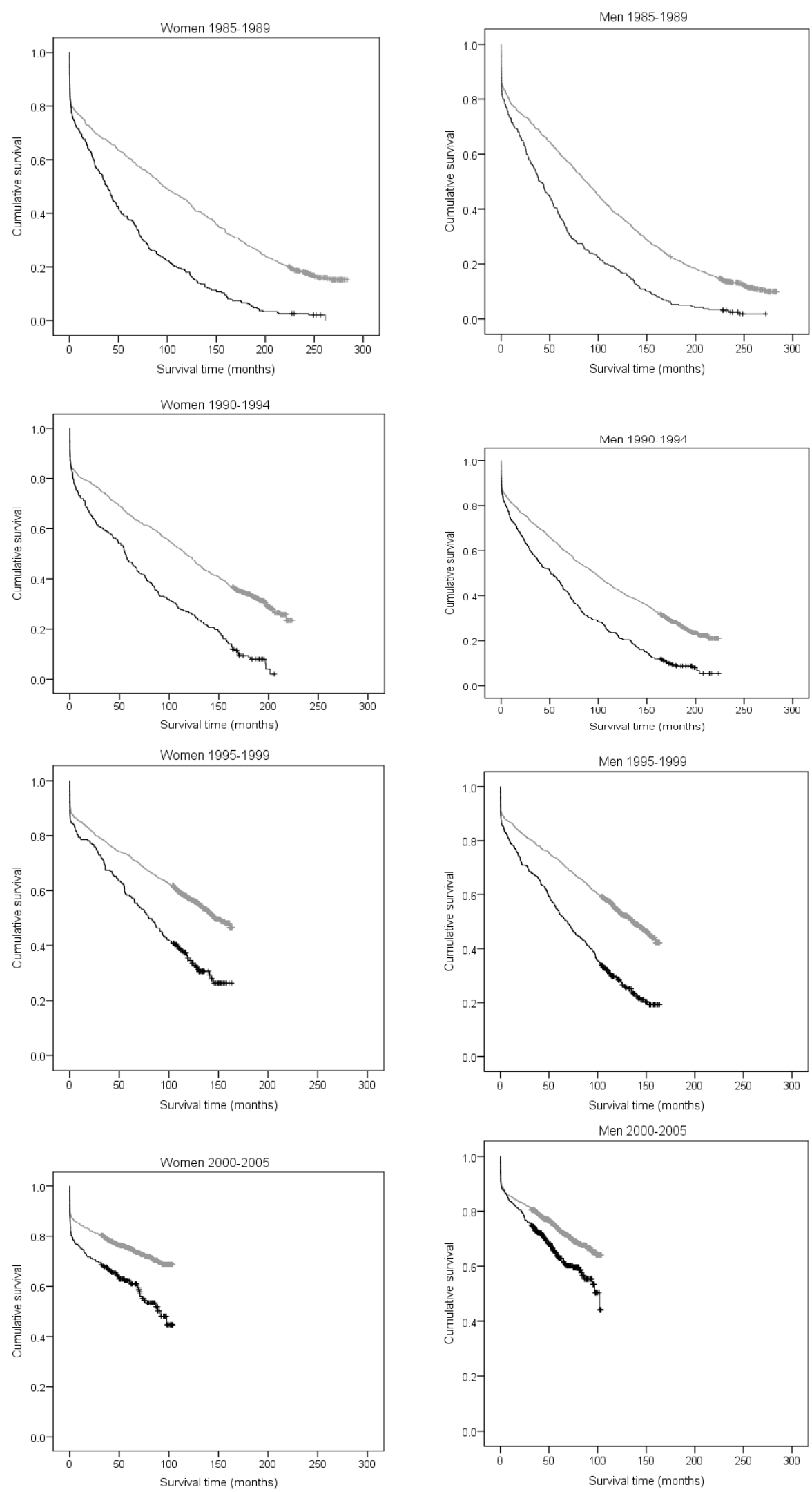
Figure 2.
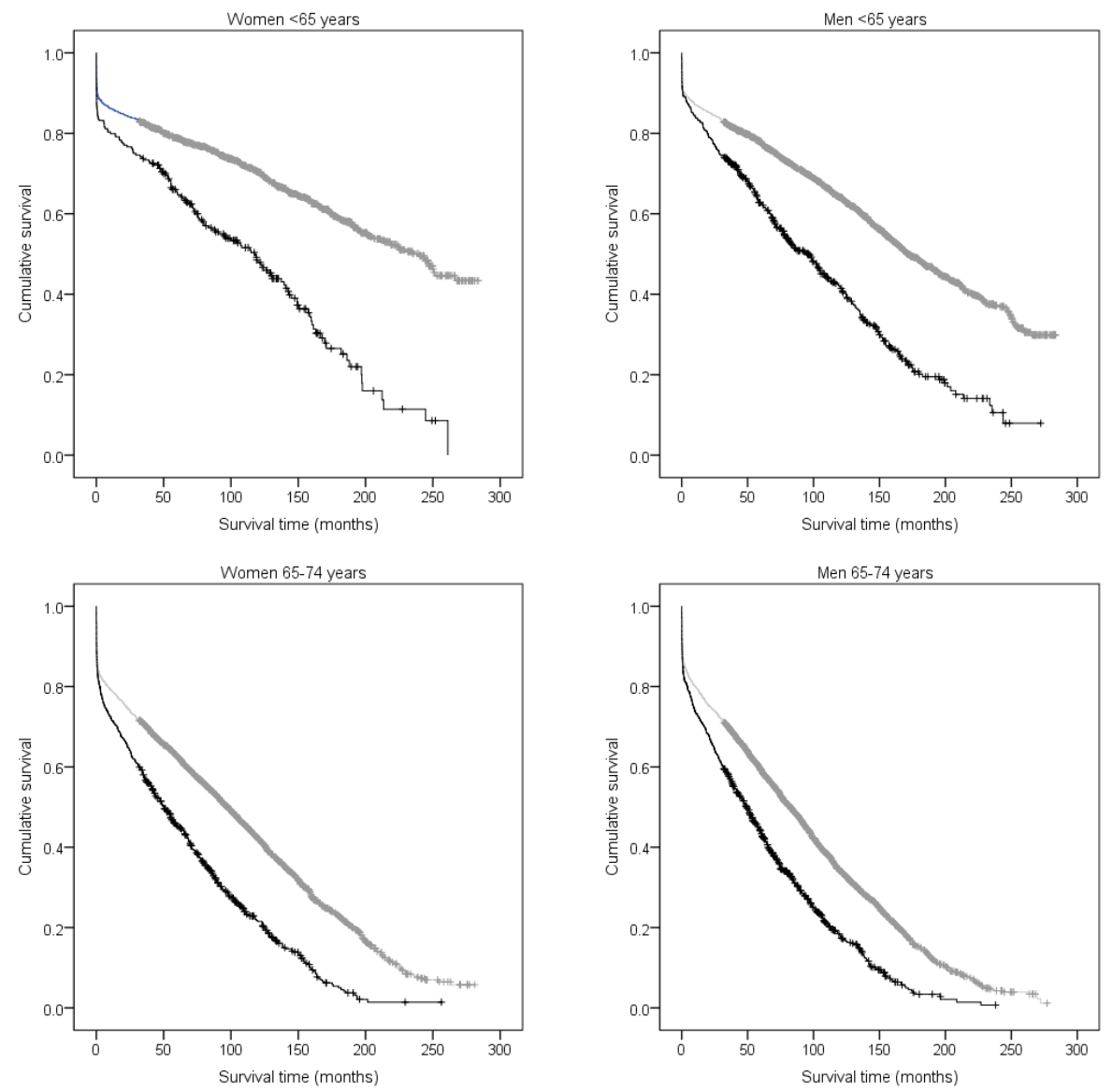